\title{
Effect of including whole linseed and vitamin E in the diet of young bulls slaughtered at two fat covers on the sensory quality of beef packaged in two different packaging systems
}

\author{
Pere Albertí, a* María M Campo, b María J Beriain, C Guillermo Ripolla \\ and Carlos Sañudo b
}

Abstract

BACKGROUND: Forty-sixPirenaica young bulls, slaughteredattwolevelsoffatness ( 3 and $4 \mathrm{~mm}$ ), were used to evaluate the effect of the inclusion of $50 \mathrm{~g} \mathrm{~kg}^{-1}$ linseed alone or with $200 \mathrm{IU}$ vitamin $\mathrm{E} \mathrm{kg}^{-1}$ in the concentrate and of the meat packaging system (vacuum or modified atmosphere packaging (MAP)) on the beef sensory quality.

RESULTS: The inclusion of linseed or supplementation with vitamin E in the concentrate induced no significant differences in the main meat sensory scores and overall appraisal except under MAP, where small differences due to concentrate ingredients were foundinjuicinessandmetallicflavor intensity. Extendingthedisplaytimeupto4or8daysinhigh-oxygen MAPhaddetrimental effectsonsensoryattributes. Meat fromanimalswith4 $\mathrm{mm}$ fatcoverdepthwereratedmoretenderandjuicy, lessfibrousand with a higher intensity of beef flavor and rancid odor than meat from $3 \mathrm{~mm}$ fat cover bulls when both samples were vacuum packaged.

CONCLUSION: The inclusion of $50 \mathrm{~g} \mathrm{~kg}^{-1}$ linseed in the concentrate fed to bulls had no detrimental effect on the beef sensory quality. The vacuum-packaged meat of bulls slaughtered at $4 \mathrm{~mm}$ fat cover was rated higher on sensory analysis than that at $3 \mathrm{~mm}$ fat cover.

Keywords: linseed; fatty acid profile; muscle color; beef

\section{INTRODUCTION}

The consumer at the moment of purchase judges the quality of meat based on intrinsic and extrinsic cues. For many consumers, color, price, visible fat and joint appearance are the most impor- tant factors when purchasing beef, while tenderness, flavor and juiciness are important factors linked to eating satisfaction. ${ }^{1}$ Many consumers preferlean beef, because meat is scored by the quantity and quality of fat present, as fat has been linked to cardiovascular diseases. 2,3 However, consumer valuation of nutritional and health claims varies across countries, and different marketing strategies are possible. ${ }^{4}$ Therefore many consumers prefer lean beef as evi- dence of healthiness and also support the development of tech- nologies that can improve the health attributes of meat products and guarantee eating quality. ${ }^{5}$

Prime beef cuts can be aged in vacuum packaging before being cut into steaks and sold by the butcher or placed on trays for selfservice displays. Vacuum-packaged beef has a purple or brown appearance, making it visually unappealing to most con- sumers. Therefore, seeking the best appearance for beef, modified atmosphere packaging (MAP) has been imposed on over-wrapped trays. However, aging in MAP raises some issues, as oxygen pro- motes oxidation of lipids and pigments ${ }^{6}$ and has negative influ- ences on shear force, ${ }^{7}$ thawing losses and sensoryquality. ${ }^{8}$
Feedstuffs rich in polyunsaturated fatty acids are being used to improve the fatty acid profile of beef. ${ }^{9}$ The increase in polyunsaturated fatty acids in intramuscular fat can increase lipid oxidation during retail display ${ }^{10}$ or can reduce some palatability attributes. ${ }^{11}$ However, the eating quality of the cattle that receive linseed does not always differ from the control. ${ }^{10}$ Regarding the fatty acids of the fattening diet, it should be considered that oleic acid is gener- ally related to desirable flavors, while polyunsaturated fatty acids have been associated with unpleasantorabnormal flavors. 12

Whole linseed partially escapes ruminal biohydrogenation and increases the content of $18: 3 n-3$ in beef, decreasing the $n-6 / n-3$

* Correspondence to: P Albertí, Unidad de Tecnología en Producción Ani- mal, CITA de Aragón, Avda Montañana 930, E-50059 Zaragoza, Spain.

E-mail: palberti@aragon.es

a Centro de Investigación y Tecnología Agroalimentaria (CITA), Gobierno de Aragón, Avda Montañana 930, E-50059,Zaragoza, Spain

b Facultad de Veterinaria, Universidad de Zaragoza, C/ Miguel Servet 177,

E-50013, Zaragoza, Spain

c E.T.S. Ingenieros Agrónomos, Universidad Pública de Navarra, Campus de Arrosadia, E-31006, Pamplona, Spain

This is the peer reviewed version of the following article: Albertí, P., Campo, M.M., Beriain, M.J., Ripoll, G. and Sañudo, C. (2017), Effect of including whole linseed and vitamin E in the diet of young bulls slaughtered at two fat covers on the sensory quality of beef packaged in two different packaging systems. J. Sci. Food Agric., 97: 753-760. doi:10.1002/jsfa.7792 which has been published in final form at https://doi.org/10.1002/jsfa.7792. This article may be used for non-commercial purposes in accordance with Wiley Terms and Conditions for Use of Self-Archived Versions. 
ratio. ${ }^{13-17}$ However, these studies evaluated the performances and carcass traits but did not assess the sensory quality of the meat. Feeding bulls with concentrates that contain ingredients that increase unsaturated fatty acids in the meat increases the need for dietary vitamin E supplementation to prevent flavor deterioration due to lipid oxidation. 18

Therefore the objective of this study was to compare the effects of including whole linseed and vitamin E in the concentrate in young bulls slaughtered at two fat covers on the sensory quality of the beef packaged in two different packaging systems.

\section{EXPERIMENTAL}

\section{Animals and diets}

The experiment was carried out with 46 Pirenaica young bulls $(270.7 \pm 28.4 \mathrm{~kg}$ carcass weight) reared in six lots. Half of the animalswerefeduntiltheyreached $3 \mathrm{mmofdorsalfatcoverdepth}$, and the other half until they reached $4 \mathrm{~mm}$. Two lots were fed with each of the following diets: a control concentrate $(n=7)$, concentrate with $50 \mathrm{~g} \mathrm{~kg}^{-1}$ linseed $(n=8)$ and concentrate with $50 \mathrm{~g} \mathrm{~kg}^{-1}$ linseed plus $200 \mathrm{IU}$ vitamin $\mathrm{E} \mathrm{kg}^{-1}(n=8)$. For detailed information, see Albertí etal. ${ }^{19}$

At $24 \mathrm{~h}$ after slaughter, from the left longissimus thoracis muscle, two 2-cm-thick steaks (T5-T6) were removed, vacuum packed and frozen at $-20^{\circ} \mathrm{C}$ for proximate and vitamin E content analysis. Samples were analyzed for dry matter and ash according to official AOAC methods. ${ }^{20}$ Another sample was ground and lyophilized, the nitrogen content was assessed using a protein analyzer (NA2100, Ce Instruments, ThermoQuest Italia, Rodano, Italy) and the intra- muscular fat content was quantified using an Ankom XT10 extrac- tor (MACEDON, NY, USA). Both components were expressed as $\mathrm{kg}^{-1}$ freshmeat.

To determine the $\alpha$-tocopherol content of the muscle, $1 \mathrm{~g}$ of longissimus thoracis muscle was treated with a saponification solution, and the non-saponifiable matter was recovered by petroleum ether extraction 21 and analyzed using an Agilent 1100 high-performance liquid chromatograph (Agilent Technologies EspañaSL, LasRozas,Spain)equipped withaquaternarypump, an Atlantis dC18, $4.6 \mathrm{~mm} \times 200 \mathrm{~mm}, 3 \mu \mathrm{m}$ capillary column (Waters Cromatografía, SA, Cerdanyola del Vallès, Spain) and a fluores- cence detector $\left(\lambda_{\mathrm{ex}}=295 \mathrm{~nm}, \lambda_{\mathrm{em}}=340 \mathrm{~nm}\right)$. The mobile phase was an acetonitrile/water mixture $(95: 5 \mathrm{v} / \mathrm{v})$ with $1 \mathrm{mLL}^{-1}$ triflu- oroacetic acid. The flow rate was $0.025 \mathrm{mLs}^{-1}$, the temperature of the column oven was $35^{\circ} \mathrm{C}$ and the run time was $8 \mathrm{~min}$. No internal standard was used.

Additionally, two 2-cm-thick steaks (T11 - T12) were removed, vacuum packaged and kept at $4{ }^{\circ} \mathrm{C}$ in darkness. One was aged for 2 days and the other for 14 days, and then both were frozen at $-20^{\circ} \mathrm{C}$ for lipid oxidation analysis, which was measured with the thiobarbituric acid-reactive substances (TBARS) method of Ripoll et al. 22

From the longissimuslumborum muscle(L1-L6), two 2-cm-thick steaks werevacuum packagedindividuallyandkeptat $4{ }^{\circ} \mathrm{C}$. One was aged for 2 days and the other for 14 days, and then both were frozen at -20 ${ }^{\circ} \mathrm{C}$ for sensory analysis. Located next to the previous sample, a $6 \mathrm{~cm}$ section was cut, vacuum packed and aged for 7 days at $4{ }^{\circ} \mathrm{C}$. Afterwards, three 2 -cm-thick steaks were cut. One was directly vacuum packed and frozen at $-20^{\circ} \mathrm{C}$. The other two were packed in a modified atmosphere consisting of polyethylene trays with an $80 \%$ $\mathrm{O}_{2} / 20 \% \mathrm{CO}_{2}$ gas mixture (Praxair, Zaragoza, Spain) sealed with a polyethylene/polyamide laminate film (30 $\mu \mathrm{m}$, water vapor

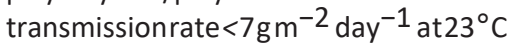

and $85 \%$ relative humidity $(\mathrm{RH}), \mathrm{O}_{2}$ transmission rate $<15 \mathrm{~cm}^{3} \mathrm{~m}^{-2}$ day $^{-1}$ at $23{ }^{\circ} \mathrm{C}$ and $0 \% \mathrm{RH}, \mathrm{CO}_{2}$ transmission rate $<75 \mathrm{~cm}^{3} \mathrm{~m}^{-2}$ day $^{-1}$ at $23^{\circ} \mathrm{C}$ and $0 \% \mathrm{RH}$; Linpac Packaging SL, Linpac plastic pontivy S.A., Noyal-Pontivy, France). The trays were placed into a vertical retail display at $3 \pm 1^{\circ} \mathrm{C}$ and fluorescently lit with $1400 \mathrm{~lx}$ intensity for $12 \mathrm{~h}$ a day for a duration of either 4 or 8 days. After this displaytime, sampleswerevacuum packagedand frozenat $-20{ }^{\circ} \mathrm{C}$ for sensory analysis.

\section{Sensory evaluation}

Beef samples were thawed for $24 \mathrm{~h}$ at $4{ }^{\circ} \mathrm{C}$. Steaks were cooked on a double-hotplategrill(SammicP8D2,SammicS.L., Azcoitia Guipuzkoa, Spain) at $200{ }^{\circ} \mathrm{C}$ until their internal temperature reached $70^{\circ} \mathrm{C}$. Sample temperature was monitored with a ther- mocouple probe (Jenway 2000, Bibby Scientific Ltd., Essex, UK) inserted horizontally at the steak midpoint.

Each steak was cut into nine pieces of approximately $2 \mathrm{~cm}$ per side and then wrapped individually in aluminum foil and coded. Samples werekeptwarminaheaterat $60^{\circ} \mathrm{Cuntil}$ they were tasted by panelists. Evaluations were based on quantitative descriptors in a balanced incomplete block design. Panelists received samples in individual cabins under controlled environmental conditions and red light (ISO 8589:1988). The trained panel included nine persons who were previously checked for coherence for each attribute (ISO $8586-$ 1:1993). They evaluated 11 attributes: beef, lactic and rancid odor intensities; tenderness; fibrousness; juiciness; beef, metallic, lactic and rancid flavor intensities; and overall appraisal. The attribute liver flavor intensity was included on the display time panel. Panelists assessedsamplesusinga $10 \mathrm{~cm}$ unstructured line scale from $0=$ no odor detected, tough, dry or low flavor to 10 = very intense odor, very tender, very juicy or very high flavor. To avoid the possible effects of the order of presentation and carryover effects, samples were randomly presented to the panelists in each session.

The three sensory panels performed were as follows.

\section{Effect of aging time, concentrate type and fat cover}

In the first sensory analysis, to assess the effect of two aging times of meat kept under vacuum conditions from bulls fed three diets and slaughtered at two levels of fat cover thickness, panelists performed ten sessions, receiving three plates with four samples in each session for a total 120 samples.

Effectofdisplaytimeandconcentratetypeonmeatof $3 \mathrm{~mm}$ fatcover In the second sensory analysis, to assess the effect of three display times of meat in MAP from bulls fed three diets and slaughtered at $3 \mathrm{~mm}$ fat cover, panelists performed six sessions, receiving three plates with four samplesineachsessionforatotalof72samples.

Effect of display time and concentrate type on meat of $4 \mathrm{~mm}$ fatcover The third sensory analysis was similar to those previously described but performed with meatfrom $4 \mathrm{~mm}$ fat coveranimals.

\section{Statistical analysis}

A two-way analysis of variance was performed using the SAS v9.1 GLM procedure (SAS Institute Inc., Cary, NC, USA) to determine the effect of three concentrate compositions and two fat cover depths on meat analysis characteristics. The MIXED procedure was applied to calculate the least square means of the lipid oxidation during storage, with concentrate, fat cover depth and time as the fixed effects and animal as the random effect in the model. Significant 
differences between treatments were assessed using Tukey's test, with significance being determined at $P<0.05$.

The GLM procedure was used for sensory evaluations, including the mean per animal for each attribute. For the first sensory analysis (meat vacuumagedatdifferenttimes), the $3 \times 2 \times 2$ model included concentrate type, fat cover depth and time as the fixed effects and their interactions. For the second and third sensory analyses (meat packaged in MAP at different displaytimes), the $3 \times 3$ modelincludedconcentratetypeandtime as thefixed effects and their interaction. The session effect was assessed, butitwas not significant and therefore was not included in the final model. Differences between treatments were compared by treatment by applying the Tukey test.

Furthermore, with the results of the first sensory analysis and with the combination of the second and third sensory analyses, a generalized Procrustes analysis (GPA) was used to summarize the results graphically in biplots using the program XLStat 2009 (Addinsoft, Paris, France) in order to minimize differences among panelists.

\section{RESULTS AND DISCUSSION}

\section{Effect of diet on meat quality}

The fat cover at slaughter had more effect $(P<0.05)$ on the longis- simus thoracis proximal composition (except protein) than the composition of the diet $(P>0.05)$ (Table 1). The meat of carcasses with $4 \mathrm{~mm}$ subcutaneous fat thickness had higher intramuscular fat content and dry matter (14.0 and $251.3 \mathrm{~g} \mathrm{~kg}^{-1}$ respectively) than the meat from carcasses with $3 \mathrm{~mm}$ fat thickness (9.6 and

$243.5 \mathrm{~g} \mathrm{~kg}^{-1}$ respectively). Although the animals were fed concen- trate, the loin muscle had a relatively low intramuscular fat content, which corresponds to a young entire bull of a late maturing breed. These low fat contents agree with Spanish consumer preferences for lean beef as an intrinsicqualitycuerelatedtohealthquality. ${ }^{23}$

Vitamin E-enriched concentrate produced meat with a signifi- cantly higher vitamin content $(P<0.05): 1.52$ vs $0.81 \mathrm{mgkg}^{-1}$ in thecontrolgroup (Table1).Moreover, themeatofbullsfedlonger to reach thicker fat cover had significantly more vitamin con- tent $\left(1.32 \mathrm{mgkg}^{-1}\right)$ than the meat of bulls with less subcutaneous fat cover $\left(0.97 \mathrm{mg} \mathrm{kg}^{-1}\right)$. The increase in vitamin E content could increase thelipid stability and therefore the shelf lifeand sensory quality of the beef. However, these vitamin E values were lower than those obtained in meat from grass-fed animals, which usually reach over $3 \mathrm{mg} \mathrm{kg}^{-1}$.24,25 The vitamin E level in meat would have likely increasedifbullshadbeenslaughteredolderandheavier.

Lipid oxidation of vacuum-packaged meat samples was more influenced by the fat cover and aging time than by the concentrate composition (Table 2). Improvement of the fat cover resulted in a significant increase in malondialdehyde (MDA) from 0.28 to $0.54 \mathrm{mg}$ $\mathrm{kg}^{-1}$. Additionally, the lipid oxidation increased from 0.36 to $0.46 \mathrm{mg} \mathrm{MDA} \mathrm{kg}^{-1}$ when the aging time was extended from 2 to 14 days. However, the effect of including linseed or enrichment with vitamin $\mathrm{E}$ on the concentrate did not modify the levels of MDA, which were $0.4 \mathrm{mgkg}^{-1}$ on average. These low oxidation rates were due to the beef being kept vacuum packedandrefrigeratedinadarkenvironment, whicharethebest conditions to control the lipid oxidation process. 26

\section{Sensoryanalysisofbeefaffectedbyagingtime,concentrate type and fat cover}

The results are summarized in Table 3. The composition of the concentrate fed to bulls did not influence any of the sensory attributes, but the fat cover at slaughter and the aging time did significantly modify some attributes.

The beef aged 14 days was rated as more tender and less fibrous $(P<$ 0.0001 ), with greaterbeefintensityandrancidflavorthan the meataged 2 days. However, theoverallappraisal was notrelated totheseothersensory attributes. Monsónetal. ${ }^{27}$ foundthataging hada very important effect on tenderness, odor and flavor char- acteristics, but overall appraisal was not always consistent with these traits, depending on the breed effect. The juiciness remained unchangedasreported byJeremiahandGibson. ${ }^{28}$ The improve- mentoftendernessbyagingwasnotsubstantialenoughtomodify the overallappraisal.

The greatest intensity of odor and flavor of these meats was attributed to beef, followed by metallic, acid and lactic odors and flavors, with rancid having the lowest notes. It is known that unsaturated fatty acid content in beef makes it more prone to oxididation, ${ }^{29}$ giving off-flavors. However, neitherrancidodornor flavor increased in the meat from animals fed diets containing linseed or with vitamin $E$ supplementation, most likely because vacuum conditions did not favor oxidation.

The composition of the concentrate did not affect the sensory attribute values as judged by the panel. Tenderness, juiciness and flavor are the most important attributes in the variation between meat sensory assessments. ${ }^{30}$ The absence of significant differences in these attributes corresponded with a similar overall appraisal note. These results are in agreement with those reported by Maddock et al., ${ }^{11}$ who found no effects on the intensity of flavor or tenderness from 14 day vacuum-aged beef of yearling heifers that had consumed $80 \mathrm{~g} \mathrm{~kg}^{-1}$ linseed in their diet, although steaks from the control group were rated juicier than those that included linseed.

Supplementation with vitamin Ein the feed did not increase the note of positive odors or flavors, nor did it decrease off-flavors. Therefore it seems that if polyunsaturated fatty acid percentage is not increased, 19 there is no need for vitamin E supplemen- tation, because it increases costs without obtaining a positive effecton beefsensorytraits, at leastin vacuum-packaged meat. Juárez et al. ${ }^{31}$ also found no effect among treatments for sensory attributes in steaks of steers fed diets with or without $100 \mathrm{~g} \mathrm{~kg}^{-1}$ flaxseed and $600 \mathrm{IU}$ day $^{-1}$ of vitamin $\mathrm{E}$ supplementation.

The subcutaneous fat thickness of the carcass had a significant effect on sensory meat attributes, especially tenderness, fibrous- ness, juiciness, rancid odorand beefflavor. Bullsslaughtered at $4 \mathrm{~mm}$ fat cover had meat rated as more tender and juicy, less fibrous and with slightly higher rancid odor and beef flavor inten- sities than the meat of bulls slaughtered at 3 $\mathrm{mm}$. Fiems et al. ${ }^{32}$ also found a moderate correlation between fat and tenderness. In some experiments, lipid content has not been necessarily related to differences in flavor, ${ }^{33}$ but in other cases the increase in intramuscular fat improved meat flavor ${ }^{34}$ in cows. Despite the signifi- cant differences found in some of the main sensory attributes, the overall appraisal did not significantly differ between the two levels offattening. It could be that the positive differences in tenderness, juiciness and beef flavororthenegativedifferencesinrancidodor were not large enough to promote changes in overall appraisal. The results of Hunt et al., 35 however, state that when tenderness is acceptable, flavor and juiciness play a major role in determin- ing overall acceptability. Globally, fat cover effectsonmeatsensory attributes were less important than aging.

Theanalysisoftheresults ofthesensoryassessmentbypanelists obtained with GPA is shown in Fig. 1. The first two main axes explained $66.4 \%$ of the total variance. The first axis accounted for 


\begin{tabular}{|c|c|c|c|c|c|c|c|c|c|c|c|c|c|}
\hline \multirow{2}{*}{\multicolumn{2}{|c|}{ Parameter }} & \multicolumn{5}{|c|}{ Concentrate $(\mathrm{CN})$} & \multicolumn{2}{|c|}{ Fat cover $(\mathrm{F})$} & \multirow{2}{*}{$\begin{array}{l}\text { Pooled } \\
\text { SE }\end{array}$} & \multicolumn{4}{|c|}{$P$ value } \\
\hline & & \multicolumn{2}{|c|}{$C$} & $L$ & \multicolumn{2}{|c|}{$L+E$} & $3 \mathrm{~mm}$ & $4 \mathrm{~mm}$ & & \multicolumn{2}{|c|}{$\mathrm{CN}$} & $\mathrm{F}$ & $\mathrm{CN} \times \mathrm{F}$ \\
\hline \multirow{4}{*}{\multicolumn{2}{|c|}{$\begin{array}{l}\text { Dry matter }\left(\mathrm{g} \mathrm{kg}^{-1}\right) \\
\text { Protein }\left(\mathrm{g} \mathrm{kg}^{-1}\right) \\
\text { Intramuscularfat }\left(\mathrm{gkg}^{-1}\right) \\
\text { Vitamin } \mathrm{E}\left(\mathrm{mg} \mathrm{kg}^{-1}\right)\end{array}$}} & \multicolumn{2}{|c|}{244.6} & 250.4 & 246.8 & & $43.5 b$ & $251.3 a$ & 0.31 & \multicolumn{2}{|c|}{0.180} & 0.004 & 0.327 \\
\hline & & \multicolumn{2}{|c|}{222.7} & 223.1 & 219.5 & & 219.5 & 223.9 & 0.37 & \multicolumn{2}{|c|}{0.559} & 0.175 & 0.355 \\
\hline & & \multicolumn{2}{|c|}{8.6} & 13.0 & 13.4 & & $9.6 b$ & $14.0 a$ & 0.25 & \multicolumn{2}{|c|}{0.118} & 0.020 & 0.646 \\
\hline & & \multicolumn{2}{|c|}{$0.81 b$} & $1.06 a b$ & 1.5 & $2 a$ & $0.97 b$ & $1.32 a$ & 0.207 & \multicolumn{2}{|c|}{0.005} & 0.050 & 0.787 \\
\hline \multicolumn{14}{|c|}{$\begin{array}{l}\text { Values with different letters in the same row are significantly different at } P<0.05 \text {. C, control concentrate group; } \mathrm{L} \text {, linseed-supplemented concentrate } \\
\text { group; } \mathrm{L}+\mathrm{E} \text {, (linseed }+20 \mathrm{~g} \mathrm{~kg}^{-1} \text { vitamin } \mathrm{E} \text { )-supplemented concentrate group. }\end{array}$} \\
\hline \multicolumn{14}{|c|}{ Table 2. Effect of diet, fat cover and aging on oxidation (TBARS index) of vacuum-packaged meat from young Pirenaica bulls } \\
\hline \multirow[b]{2}{*}{ Parameter } & \multicolumn{2}{|c|}{ Concentrate $(\mathrm{CN})$} & \multicolumn{2}{|c|}{ Fat cover $(F)$} & \multicolumn{2}{|c|}{ Aging $(A)$} & & \multicolumn{6}{|c|}{$P$ value } \\
\hline & C L & $L+E$ & $3 \mathrm{~mm}$ & $4 \mathrm{~mm}$ & 2 days & 14 days & Pooled SE & $\mathrm{E} \mathrm{CN}$ & A & $\mathrm{CN} \times \mathrm{F}$ & $\mathrm{CN} \times \mathrm{A}$ & $\mathrm{F} \times \mathrm{A}$ & $\mathrm{CN} \times \mathrm{F} \times \mathrm{A}$ \\
\hline TBARS $^{a}$ & 0.400 .43 & 0.40 & $0.28 b$ & $0.54 a$ & $0.36 \mathrm{~b}$ & $0.46 a$ & 0.05 & 0.943 & $0.001 \quad 0.042$ & 0.407 & 0.341 & 0.056 & 0.774 \\
\hline \multicolumn{14}{|c|}{$\begin{array}{l}\text { Means with different letters are significantly different }(P<0.05) \text {. C, control concentrate group; } \mathrm{L} \text {, linseed-supplemented concentrate group; } \mathrm{L}+\mathrm{E} \text {, } \\
\left.\text { (linseed }+20 \mathrm{~g} \mathrm{~kg}^{-1} \text { vitamin } \mathrm{E}\right) \text {-supplemented concentrate group. } \\
\text { a Thiobarbituric acid-reactive substances in } \mathrm{mg} \text { malondialdehyde } \mathrm{kg}^{-1} \text {. }\end{array}$} \\
\hline
\end{tabular}

$51.1 \%$ of the variation, and the main attributes were related to tenderness $(-0.99)$, fibrousness $(0.97)$, beef flavor intensity $(-0.83)$, overall appraisal $(-0.82)$ and acid $(-0.63)$ and rancid $(-0.60)$ flavor intensities. The second axis accounted for $13.3 \%$ of the variation, and the main attributes were beef odor intensity $(-0.59)$ and juiciness (0.53). On the right side, outlined by fibrousness, the six lots of meat aged for 2 days and the lot supplemented with linseed and vitamin $E$ aged for 14 days are grouped. Located on the opposite side are the rest of the lots of 14 day aged meat, characterized by the rest of the attributes except juiciness and metallic flavor, which are placed between the two ellipses. Beef aged 14 days remains close in tenderness, beef flavor intensity and overall appraisal attributes and far in fibrousness. Most of the animals slaughtered with $4 \mathrm{~mm}$ fat cover are placed on the top and on the left of the figure; therefore they were assessed as more juicy, tender, with more beef flavor intensity and with higher overall appraisal. Animals fed control concentrate were placed in thenegativezone of the second axis, linked to a higher beefodor intensity and less juicy attributes. The beef aged 14 days from bulls fed linseed and vitamin E slaughtered with $3 \mathrm{~mm}$ fat cover was located in the same area as the 2 day aged meat, probably owing to its low intramuscular fat content $\left(9.9 \mathrm{~g} \mathrm{~kg}^{-1}\right)$ in comparison with the same diet of animals fed to $4 \mathrm{~mm}$ fat cover $\left(16.9 \mathrm{gkg}^{-1}\right)$. The effects of aging were moreimportant on meat sensoryattributes than the fat cover of the bulls.

\section{Effect of displaytimeand dietonsensoryquality of MAP packaged beef}

The results for 3 and $4 \mathrm{~mm}$ fat cover are summarized in Tables 4 and 5 respectively. Linseed inclusion in concentrate produced meat that was rated slightly more juicy by panelists but similar for all other attributes, including overall appraisal. In MAP rich in oxy- gen, some differencesinodororflavorareexpected between the meats owing to the feeding diet. In our study, linseed inclusion inconcentratedid not alter the total saturated, monounsaturated or polyunsaturated fatty acid percentages. ${ }^{19}$ However, the relative

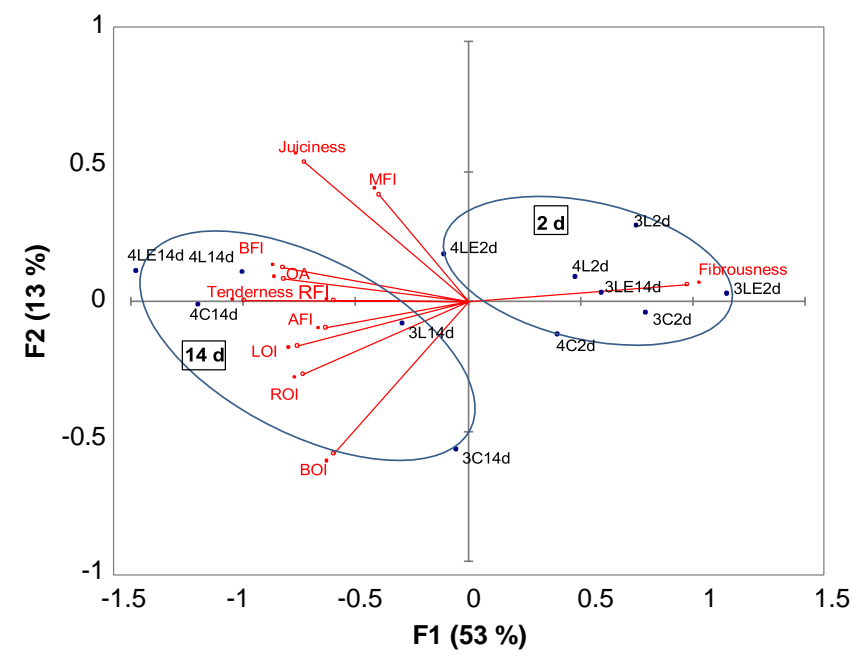

Figure 1. Plot of panel sensory attributes of vacuum-packed meat aged for 2 or 14 days of bulls fed three concentrates and slaughtered at two levels of fatness. AFI, acid flavor intensity; BFI, beef flavor intensity: $\mathrm{BOI}$, beef odor intensity; LOI, lacticodorintensity; LiFI, liver flavorintensity; $\mathrm{MFI}$, metallic flavor intensity; $\mathrm{OA}$, overall appraisal; $\mathrm{RFI}$, rancid flavor intensity; ROI, rancid odor intensity. C, control; L, linseed; LE, linseed + vitamin $\mathrm{E} ; 2 \mathrm{~d}, 2$ daysaging; $14 \mathrm{~d}, 14$ days aging; 3 , $3 \mathrm{~mm}$ fat cover; 4 ; 4 $\mathrm{mm}$ fat cover.

proportion of some polyunsaturated fatty acids was modified, significantly increasing the $n-3$ fatty acids. Therefore, as the percent- age of polyunsaturated fatty acids did not increase, there was no substrate for higher lipid oxidation.

Extending the display time to 4 or 8 days for meat packaged in MAP yielded significant differences among attributes, reducing beef odor and flavor intensity and increasing rancid odor and fla- vorintensityas well as acid flavor intensity. Although tenderness, juiciness and fibrousness were rated similarly, the overall appraisal decreased significantly with longer display times owing to the neg- ative effect of the increase in rancidity. 


\begin{tabular}{|c|c|c|c|c|c|c|c|c|c|c|c|c|c|c|c|}
\hline \multirow[b]{2}{*}{ Attribute } & \multicolumn{3}{|c|}{ Concentrate $(\mathrm{CN})$} & \multicolumn{2}{|c|}{ Fat cover $(F)$} & \multicolumn{2}{|c|}{ Aging $(A)$} & \multirow[b]{2}{*}{ SEM } & \multicolumn{7}{|c|}{$P$ value } \\
\hline & $\mathrm{C}$ & $\mathrm{L}$ & $L+E$ & $3 \mathrm{~mm}$ & $4 \mathrm{~mm}$ & 2 days & 14 days & & $\mathrm{CN}$ & $\mathrm{F}$ & A & $\mathrm{CN} \times \mathrm{F}$ & $\mathrm{CN} \times \mathrm{A}$ & $F \times A$ & $\mathrm{CN} \times \mathrm{F} \times \mathrm{A}$ \\
\hline Beef odor intensity & 4.80 & 4.76 & 4.70 & 4.73 & 4.77 & 4.70 & 4.81 & 0.137 & 0.474 & 0.448 & 0.087 & 0.402 & 0.232 & 0.479 & 0.871 \\
\hline Lactic odor intensity & 1.57 & 1.48 & 1.42 & 1.45 & 1.53 & 1.44 & 1.55 & 0.151 & 0.251 & 0.283 & 0.135 & 0.302 & 0.203 & 0.520 & 0.935 \\
\hline Rancid odor intensity & 1.09 & 1.03 & 1.07 & $1.00 b$ & $1.15 a$ & 1.02 & 1.11 & 0.107 & 0.620 & 0.001 & 0.078 & 0.748 & 0.229 & 0.842 & 0.997 \\
\hline Tenderness & 4.60 & 4.67 & 4.59 & $4.31 b$ & $4.93 a$ & $4.22 b$ & $5.01 a$ & 0.299 & $0.889<$ & $<0.000 \mathrm{~K}$ & $<0.0001$ & 0.078 & 0.768 & 0.108 & 0.956 \\
\hline Fibrousness & 5.87 & 5.81 & 5.78 & $5.95 a$ & $5.69 b$ & $6.06 a$ & $5.59 b$ & 0.214 & 0.7360 & $0.014<0$ & 0.0001 & 0.419 & 0.735 & 0.649 & 0.751 \\
\hline Juiciness & 4.03 & 4.12 & 4.15 & $4.00 b$ & $4.21 a$ & 4.07 & 4.13 & 0.186 & 0.525 & 0.013 & 0.499 & 0.405 & 0.964 & 0.152 & 0.566 \\
\hline Beef flavor intensity & 5.40 & 5.36 & 5.41 & $5.31 b$ & $5.46 a$ & $5.29 b$ & $5.48 a$ & 0.129 & 0.834 & 0.016 & 0.003 & 0.032 & 0.688 & 0.653 & 0.462 \\
\hline Metallic flavorintensity & 3.14 & 3.14 & 3.27 & 3.17 & 3.20 & 3.16 & 3.21 & 0.148 & 0.219 & 0.716 & 0.418 & 0.326 & 0.660 & 0.296 & 0.215 \\
\hline Acid flavor intensity & 2.90 & 2.87 & 2.90 & 2.82 & 2.95 & 2.82 & 2.96 & 0.158 & 0.961 & 0.092 & 0.072 & 0.973 & 0.405 & 0.346 & 0.113 \\
\hline Rancid flavor intensity & 1.22 & 1.27 & 1.33 & 1.23 & 1.31 & $1.20 b$ & $1.35 a$ & 0.117 & 0.278 & 0.177 & 0.011 & 0.761 & 0.049 & 0.855 & 0.581 \\
\hline Overall appraisal & 4.23 & 4.18 & 4.14 & 4.11 & 4.27 & 4.11 & 4.26 & 0.188 & 0.730 & 0.082 & 0.108 & 0.050 & 0.506 & 0.426 & 0.742 \\
\hline
\end{tabular}

Table 4. Means of sensory evaluation by trained panel of beef at different display times in MAP of young Pirenaica bulls slaughtered at $3 \mathrm{~mm}$ subcutaneous fat cover

\begin{tabular}{|c|c|c|c|c|c|c|c|c|c|c|}
\hline \multirow[b]{2}{*}{ Attribute } & \multicolumn{3}{|c|}{ Concentrate $(\mathrm{CN})$} & \multicolumn{3}{|c|}{ Display time $(\mathrm{T})$} & \multirow[b]{2}{*}{ SEM } & \multicolumn{3}{|c|}{$P$ value } \\
\hline & C & $\mathrm{L}$ & $L+E$ & 0 days & 4 days & 8 days & & $\mathrm{CN}$ & $\mathrm{T}$ & $\mathrm{CN} \times \mathrm{T}$ \\
\hline Beef odor intensity & 4.02 & 4.07 & 4.02 & $4.67 a$ & $3.95 b$ & $3.50 c$ & 0.201 & 0.882 & $<0.0001$ & 0.099 \\
\hline Lactic odor intensity & 1.08 & 1.32 & 1.19 & 1.25 & 1.17 & 1.17 & 0.133 & 0.077 & 0.062 & 0.616 \\
\hline Rancid odor intensity & 1.43 & 1.58 & 1.40 & $1.09 b$ & $1.54 a$ & $1.78 a$ & 0.156 & 0.242 & $<0.0001$ & 0.300 \\
\hline Tenderness & 4.33 & 4.42 & 4.28 & 4.36 & 4.37 & 4.30 & 0.268 & 0.841 & 0.981 & 0.566 \\
\hline Fibrousness & 5.81 & 5.71 & 5.85 & 5.83 & 5.71 & 5.84 & 0.228 & 0.800 & 0.872 & 0.624 \\
\hline Juiciness & $3.52 b$ & $3.75 a b$ & $3.90 a$ & 3.87 & 3.77 & 3.53 & 0.181 & 0.043 & 0.053 & 0.616 \\
\hline Beef flavor intensity & 4.11 & 4.18 & 4.27 & $4.74 a$ & $4.10 b$ & $3.71 c$ & 0.187 & 0.466 & $<0.0001$ & 0.240 \\
\hline Liver flavor intensity & 1.57 & 1.65 & 1.59 & 1.50 & 1.62 & 1.69 & 0.101 & 0.689 & 0.062 & 0.411 \\
\hline Metallic flavor intensity & 2.83 & 2.80 & 2.79 & 2.77 & 2.80 & 2.85 & 0.097 & 0.964 & 0.698 & 0.477 \\
\hline Acid flavor intensity & 2.70 & 2.63 & 2.68 & $2.52 b$ & $2.59 b$ & $2.91 a$ & 0.154 & 0.845 & 0.006 & 0.519 \\
\hline Rancid flavor intensity & 2.18 & 2.27 & 2.04 & $1.15 c$ & $2.18 b$ & $3.17 a$ & 0.180 & 0.174 & $<0.0001$ & 0.272 \\
\hline Overall appraisal & 3.82 & 3.80 & 3.80 & $4.35 a$ & $3.85 b$ & $3.22 c$ & 0.187 & 0.984 & $<0.0001$ & 0.548 \\
\hline
\end{tabular}

Means with different letters in the same row are significantly different $(P<0.05)$. C, control concentrate group; L, linseed-supplemented concentrate group; $\mathrm{L}+\mathrm{E}$, (linseed $+20 \mathrm{~g} \mathrm{~kg}^{-1}$ vitamin $\left.\mathrm{E}\right)$-supplemented concentrate group.

The vitamin $\mathrm{E}$ and linseed supplements improved the juiciness in relation to the control group. No significant differences were found between the other sensory attributes, including overall appraisal. The indication of no significant effect of linseed or vitamin $E$ on the beef sensory characteristics in our study agrees with the results of one study, ${ }^{31}$ but other studies, including a diet containing $100 \mathrm{~g} \mathrm{~kg}^{-1}$ ground flaxseed, have described detrimental effects due to more pronounced off-flavors, evenifflavorintensitydidnot differ. ${ }^{36}$

The results obtained with GPAin meat packaged in MAP and dis- played for 8 days from bulls slaughtered at 3 and $4 \mathrm{~mm}$ fat depth are presented in Fig. 2. The first axis accounted for $57.1 \%$ of the variation, and the main attributes were related to rancid flavor intensity $(-0.99)$, overall appraisal (0.97), beef odor (0.93) and fla- vor (0.91) intensities, rancid odor intensity $(-0.84)$ and acid $(-0.77)$ and liver $(-0.63)$ flavor intensities. The second axis accounted for $16.5 \%$ of the variation, and the main attribute was metallic flavor intensity (0.66). The tenderness and fibrousness vectors appeared next, which indicates that 7 days of aging was enough to reach adequate tenderness, and no additional improvement in tex- ture was achieved during display time. Therefore tenderness and fibrousnessattributes explainedaresidual part of thevariability of the sensory evaluation. This confirms the lack of statistical signifi- cance of tenderness on the previous statistical analysis.

In Fig. 2, from the right side to the left side, the meat is grouped by timeondisplay. Thehighestincreaseinoverallappraisal, beef odor and flavor intensities corresponds to meat that was not on display. In the opposite zone are the six lots of meat displayed for 8 days, which were characterized by high rancid flavor and odor intensity. On the top part of the graph, the meat of bulls with $3 \mathrm{~mm}$ depth fat cover is linked to metallic flavor intensity, while at the bottom there is the meat of animals with $4 \mathrm{~mm}$ fat cover, which was characterized by acid and liver flavor intensities. It should be noted that thetwo distribution areasfor the 3 and $4 \mathrm{~mm}$ fat cover animals may correspond also to the two sensory assessments performed, because both are confounding factors for the GPA.

The most valued meat was that of bulls slaughtered at 3 or $4 \mathrm{~mm}$ fat cover, previously aged for 7 days in vacuum and then 
PAlbertí etal.

\begin{tabular}{|c|c|c|c|c|c|c|c|c|c|c|}
\hline \multirow[b]{2}{*}{ Attribute } & \multicolumn{3}{|c|}{ Concentrate $(\mathrm{CN})$} & \multicolumn{3}{|c|}{ Display time $(\mathrm{T})$} & \multirow[b]{2}{*}{ SEM } & \multicolumn{3}{|c|}{$P$ value } \\
\hline & C & $\mathrm{L}$ & $L+E$ & 0 days & 4 days & 8 days & & $\mathrm{CN}$ & $\mathrm{T}$ & $\mathrm{CN} \times \mathrm{T}$ \\
\hline Beef odor intensity & 4.16 & 4.38 & 4.44 & $4.63 a$ & $4.38 b$ & $3.87 c$ & 0.189 & 0.237 & $<0.0001$ & 0.379 \\
\hline Lactic odor intensity & 1.27 & 1.30 & 1.48 & 1.49 & 1.37 & 1.20 & 0.183 & 0.617 & 0.173 & 0.669 \\
\hline Rancid odor intensity & 1.69 & 1.44 & 1.50 & $1.31 b$ & $1.58 a b$ & $1.71 a$ & 0.171 & 0.139 & 0.012 & 0.996 \\
\hline Tenderness & 4.21 & 4.19 & 4.34 & 4.15 & 4.29 & 4.30 & 0.333 & 0.870 & 0.905 & 0.663 \\
\hline Fibrousness & 5.68 & 5.68 & 5.59 & 5.72 & 5.66 & 5.57 & 0.255 & 0.732 & 0.914 & 0.630 \\
\hline Juiciness & 3.55 & 3.60 & 3.84 & 3.82 & 3.63 & 3.57 & 0.246 & 0.439 & 0.307 & 0.222 \\
\hline Beef flavor intensity & 4.93 & 5.0 & 5.11 & $5.31 a$ & $5.05 a$ & $4.68 b$ & 0.234 & 0.246 & $<0.0001$ & 0.367 \\
\hline Liver flavor intensity & 1.64 & 1.72 & 1.74 & 1.69 & 1.72 & 1.69 & 0.145 & 0.635 & 0.786 & 0.674 \\
\hline Metallic flavor intensity & $2.66 a$ & $2.35 b$ & $2.51 a b$ & 2.54 & 2.43 & 2.55 & 0.136 & 0.029 & 0.538 & 0.729 \\
\hline Acid flavor intensity & 2.93 & 2.73 & 2.91 & $2.71 b$ & $2.72 b$ & $3.13 a$ & 0.158 & 0.131 & 0.008 & 0.113 \\
\hline Rancid flavor intensity & 2.59 & 2.25 & 2.41 & $1.16 c$ & $2.38 b$ & $3.64 a$ & 0.256 & 0.345 & $<0.0001$ & 0.471 \\
\hline Overall appraisal & 3.56 & 3.60 & 3.75 & $4.26 a$ & $3.75 b$ & $2.95 c$ & 0.228 & 0.458 & $<0.0001$ & 0.509 \\
\hline
\end{tabular}

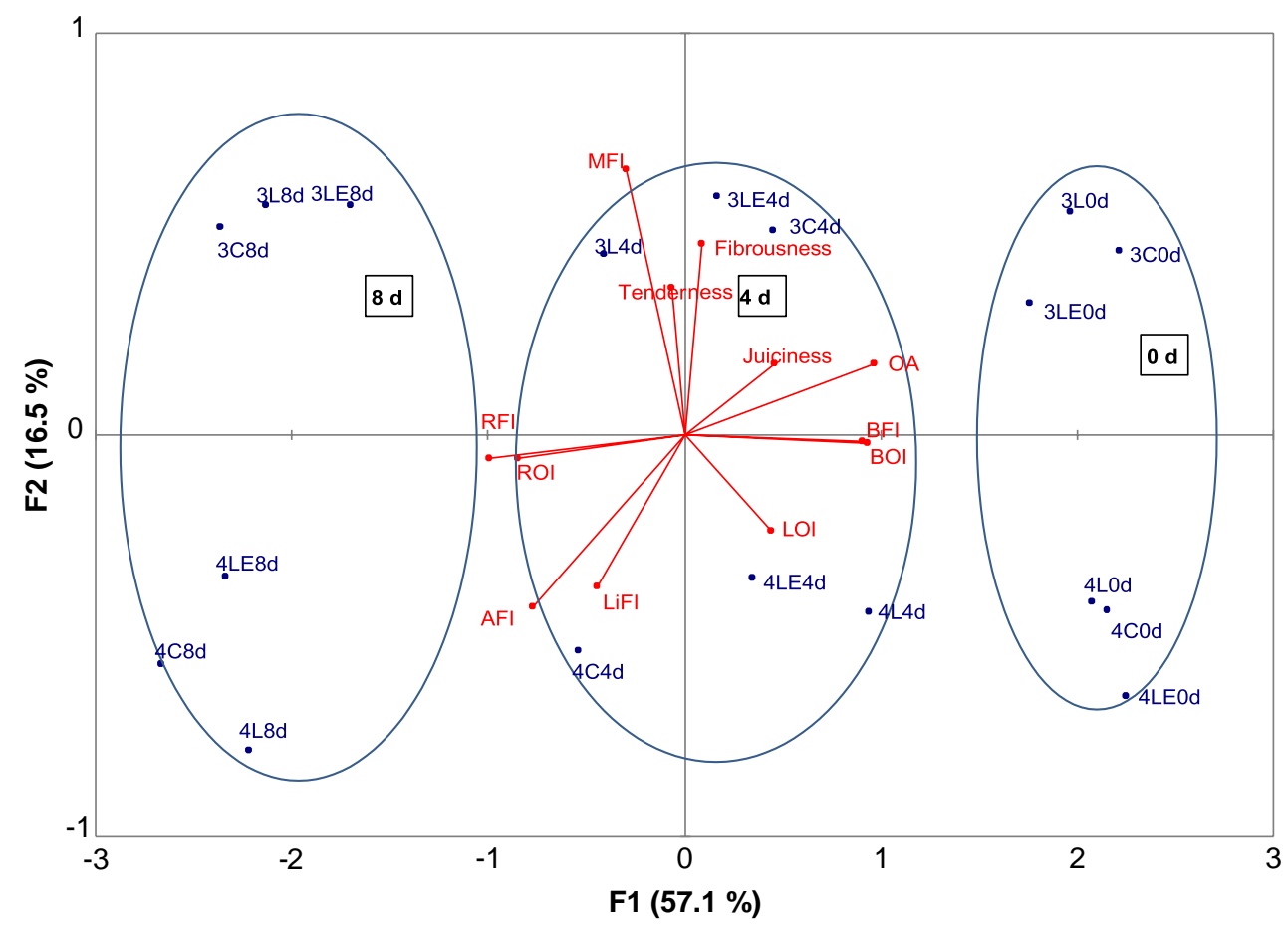

Figure 2. Plot of panel sensory attributes of beef aged 7 days, MAP packed and displayed for 0,4 or 8 days of bulls fed three concentrates and slaughtered at two levels of fatness. $0 \mathrm{~d}$, no display; $4 \mathrm{~d}$, 4 days display; $8 \mathrm{~d}, 8$ days display. See Fig. 1 for explanation of other abbreviations used.

packed in MAP at the initial time of display. In contrast to the MAP, the anaerobic environment of the vacuum-packed meat limited the rancidity. ${ }^{8}$ Thus rancid flavor increased slightly and rancid odor did not change significantly. When samples did not differ in tenderness, the larger sensory difference between lots was flavor, odor or juiciness, 35,37 which all play a major role in determining the overall acceptability. Nevertheless, consumers usually do not detect oxidation flavors until oxidation products have reached a level of at least $2 \mathrm{mg}$ MDA kg ${ }^{-1}$ tissue. ${ }^{38-40}$

The results of this study suggest that the effect of linseed or vitamin E enrichment of feed for young bulls was less important on the meat sensory assessment than the effect of the fat cover of the carcasses and was much less important than aging time or packaging procedures. The vacuum-packaged meat of bulls slaughtered at $4 \mathrm{~mm}$ fat cover was rated higher on sensory analysis than that at $3 \mathrm{~mm}$ fat cover. The meat of young Pirenaica bulls mightbe aged in vacuum for less than 7 days and then sold directly to retail customers for cutting and display in MAP for a short time in order to ensure tenderness and few negative flavors.

\section{CONCLUSIONS}

The inclusion of $50 \mathrm{~g} \mathrm{~kg}^{-1}$ linseed or supplementation with $200 \mathrm{IU}$ vitamin $\mathrm{E} \mathrm{kg}^{-1}$ in the concentrate fed to bulls had no 
significant effect on the main beef sensory attribute scores. Aging time in a vacuum package and display time of aged beef had significant effects on sensory rating. Fat cover of the carcass improved the sensory ratings of tenderness and juiciness, espe- cially in vacuum-packaged meat. Meat aged for 14 days in vacuum was rated less fibrous and tenderer, with more beef flavor intensity but also a more intense rancid flavor, than meat aged for only 2 days. In vacuum-aged beef later packaged in MAP, an increase in display time significantly increased the intensity of negative notes such as rancid odor and flavor and decreased positive notes such as beef odor, lowering the overall appraisal.

\section{ACKNOWLEDGEMENT}

This research was supported by INIA of Spain, project RTA $2005-00183$.

\section{REFERENCES}

1 Robbins K, Jensen J, Ryan KJ, Homco-Ryan C, McKeith FK and Brewer MS, Consumer attitudes towards beef and acceptability of enhanced beef. MeatSci 65:721-729 (2003).

2 EFSA, Scientific report of EFSA. Outcome of the public consultation on the DraftOpinion of theScientificPanelon DieteticProducts, Nutri- tion, and Allergies (NDA) on Dietary Reference Values for fats, includ- ing saturated fatty acids, polyunsaturated fatty acids, monounsatu- rated fatty acids, transfattyacids, and cholesterol.EFSAJ8(5):1507 (2010).

3 McNeill SH, Harris KB, Field TG and Van Elswyk ME, The evolution of lean beef: identifying lean beef in today's U.S. marketplace. Meat Sci 90:1-8 (2012).

4 Van Wezemael L, Caputo V, Nayga Jr RM, Chryssochoidis G and Verbeke W, European consumer preferences for beef with nutrition and health claims: a multi-country investigation using discrete choice experiments. Food Pol 44:167-176 (2014).

5 Verbeke W, Van Wezemael L, de Barcellos MD, Kügler JO, Hocquette J-F, Ueland $\varnothing$, etal., European beef consumers' interest in a beef eatingquality guarantee: insights from a qualitative study in four EU countries. Appetite 54:289-296 (2010).

6 Jakobsen $\mathrm{M}$ and Bertelsen $\mathrm{G}$, Colour stability and lipid oxidation of fresh beef. Development of a response surface model for predicting theeffects of temperature, storage time, and modified atmosphere composition. MeatSci 54:49-57 (2000).

7 Seyfert M, Hunt MC, Mancini RA, Hachmeister KA, Kropf DH, Unruh JA, et al., Beef quadriceps hot boning and modified-atmosphere packaging influence properties of injection-enhanced beef round muscles. J Anim Sci 83:686-693 (2005).

8 Lagerstedt Å, Lundström K and Lindahl G, Influence of vacuum or highoxygen modified atmosphere packaging on quality of beef M. longissimus dorsi steaks after different ageing times. Meat Sci 87:101 - 106 (2011).

9 Wood JD, Richardson RI, Nute GR, Fisher AV, Campo MM, Kasapidou E, etal., Effects of fatty acids on meat quality: a review. Meat Sci 66:21-32 (2003).

10 Vatansever L, Kurt E, Enser M, Nute GR, Scollan ND, Wood JD, et al., Shelf life and eating quality of beef from cattle of different breeds given diets differing in $n$-3 polyunsaturated fattyacid composition.Anim Sci 71:471 $-482(2000)$

11 Maddock TD, Bauer ML, Koch KB, Anderson VL, Maddock RJ, BarceloCoblijn $\mathrm{G}$, et al., Effect of processing flax in beef feedlot diets on performance, carcass characteristics, and trainedsensory panel ratings. JAnim Sci 84:1544-1551 (2006).

12 Duckett SK, Wagner DG, Yates LD, Dolezal HG and May SG, Effects of time on feed on beef nutrient composition.JAnimSci 71:2079-2088 (1993).

13 Corazzin M, Bovolenta S, Sepulcri A and Piasentier E, Effect of whole lin- seed addition on meat production and quality of Italian Simmental and Holstein young bulls. MeatSci 90:99-105 (2012).

14 Juárez M, Dugan MER, Aalhus JL, Aldai N, Basarab JA, Baron VS, et al., Effects of vitamin $E$ and flaxseed on rumen-derived fatty acid intermediates in beef intramuscular fat. Meat Sci 88:434-440 (2011).
15 Mach N, Devant M, Diaz I, Font-Furnols M, Oliver MA, Garcia JA, et al., Increasingtheamount of $n$ - 3 fattyacidinmeatfromyoung Holstein bulls through nutrition. JAnim Sci 84:3039-3048(2006).

16 RaesK, HaakL, Balcaen A, ClaeysE, Demeyer Dand DeSmetS, Effect of linseed feeding at similar linoleic acid levels on the fatty acid composition of double-muscled Belgian Blue young bulls. Meat Sci 66:307-315 (2004).

17 Scollan N, Hocquette JF, Nuernberg K, Dannenberger D, Richard- son I and Moloney A, Innovations in beef production systems that enhance the nutritional and health value of beef lipids and their relationship with meat quality. Meat Sci 74:17 - 33 (2006).

18 Wood JD and Enser DM, Factors influencing fatty acids in meat and the role of antioxidants in improving meat quality. BrJNutr 78:S49-S60 (1997).

19 AlbertíP, Beriain MJ, RipollG, SarriésV, Panea B, Mendizabal JA, etal., Effect of including linseed in a concentrate fed to young bulls on intramuscular fatty acids and beefcolor. MeatSci96:1258-1265 (2014).

20 AOAC, Official Methodsof Analysis (17th rev. edn). Association of Official Analytical Chemists, Washington, DC (2000).

21 Liu Q, Scheller KK and Schaefer DM, A simplified procedure for vita- min E determination in beef muscle. J Anim Sci 74:2406-2410 (1996).

22 Ripoll G, Joy M and Muñoz F, Use of dietary vitamin E and selenium (Se) to increase the shelf life of modified atmosphere packaged light lamb meat. Meat Sci 87:88-93 (2011).

23 Realini CE, Kallas Z, Pérez-Juan M, Gómez I, Olleta JL, Beriain MJ, et al., Relative importance of cues underlying Spanish consumers' beef choice and segmentation, and consumer liking of beef enriched with $n-3$ and CLAfattyacids. FoodQualPrefer 33:74-85 (2014).

24 Realini CE, Duckett SK, Brito GW, Dalla Rizza M and De Mattos D, Effect of pasture vs. concentrate feeding with or without antioxidants on carcass characteristics, fatty acid composition, and quality of Uruguayan beef. MeatSci66:567-577 (2004).

25 YangA, LanariMC, BrewsterMandTumeRK, Lipidstabilityand meat colour of beef from pasture- and grain-fed cattle with or without vitamin $E$ supplement. Meat Sci 60:41-50 (2002).

26 Franco D, González L, Bispo E, Latorre A, MorenoT, Sineiro J, etal., Effects of calf diet, antioxidants, packaging type and storage time on beef steak storage. MeatSci 90:871-880(2012).

27 Monsón F, Sañudo C and Sierra I, Influence of breed and ageing time on the sensory meat quality and consumer acceptability in intensively reared beef. MeatSci 71:471-479(2005).

28 Jeremiah LE and Gibson LL, The effects of postmortem product han- dling andagingtimeonbeefpalatability. Food Res/nt36:929-941 (2003).

29 Warren HE, Scollan ND, Nute GR, Hughes SI, Wood JD and Richardson RI, Effects of breed and a concentrate or grass silage diet on beef quality in cattle of 3 ages. II: Meatstabilityandflavour. MeatSci78:270-278 (2008).

30 Rødbotten M, Kubber $\varnothing \mathrm{dE}$, LeaP and Ueland $\varnothing$, A sensory map of the meat universe. Sensory profile of meat from 15 species. MeatSci 68:137-144 (2004).

31 Juárez M, Dugan MER, Aldai N, Basarab JA, Baron VS, McAllister TA, et al., Beef quality attributes as affected by increasing the intramuscular levels of vitamin Eand omega-3 fattyacids. MeatSci90:764-769 (2012).

32 Fiems LO, De Campeneere S, De Smet S, Van de Voorde G, Vanacker JM and Boucque CV, Relationship between fat depots in carcasses of beef bulls and effect on meat colour and tenderness. Meat Sci 56:41-47 (2000).

33 Melton SL, Effects of feeds on flavor of red meat: a review. JAnim Sci 68:4421 - 4435 (1990).

34 Vestergaard M, Madsen NT, Bligaard HB, Bredahl L, Rasmussen PT and Andersen HR, Consequences of two or four months of fin- ishing feeding of culled dry dairy cows on carcass characteristics and technological and sensory meat quality. Meat Sci 76:635-643 (2007).

35 Hunt MR, Garmyn AJ, O'Quinn TG, Corbin CH, Legako JF, Rathmann RJ, etal., Consumer assessment of beef palatability from four beef muscles from USDA Choice and Select graded carcasses. Meat Sci 98:1-8 (2014).

36 LaBrune HJ, Reinhardt CD, Dikeman ME and Drouillard JS, Effects of grain processingand dietarylipid sourceon performance, carcass 
characteristics, plasma fatty acids, and sensory properties of steaks from finishing cattle. J Anim Sci 86:167-172 (2008).

37 Sitz BM, Calkins CR, Feuz DM, Umberger WJ and Eskridge KM, Consumer sensory acceptance and value of domestic, Canadian, and Australian grass-fed beef steaks. J Anim Sci 83:2863-2868 (2005).

38 Campo MM, Nute GR, Hughes SI, Enser M, Wood JD and Richardson RI, Flavour perception of oxidation in beef. Meat Sci 72:303311 (2006).
39 Greene BE and Cumuze TH, Relationship between TBA numbers and inexperienced panelists' assessments of oxidized flavor in cooked beef. J Food Sci 47:52-54 (1982).

40 Zakrys PI, Hogan SA, O'Sullivan MG, Allen P and Kerry JP, Effects of oxygen concentration on the sensory evaluation and quality indicators of beef muscle packed under modified atmosphere. Meat Sci 79:648-655 (2008). 